\title{
Thioridazine has potent antitumor effects on lung cancer stem-like cells
}

\author{
JIANI SHEN ${ }^{1}$, BUYUN MA ${ }^{1}$, XINMIN ZHANG $^{1}$, XIAOZHU SUN $^{1}$, JIANCUI HAN $^{1}$, \\ YIGANG WANG $^{1}$, LIANG CHU ${ }^{2}$, HAINENG XU ${ }^{3}$ and YU YANG $^{1,2}$ \\ ${ }^{1}$ Xinyuan Institute of Medicine and Biotechnology, School of Life Sciences, Zhejiang Sci-Tech University, Hangzhou, \\ Zhejiang 310018; ${ }^{2}$ Institute of Biochemistry and Cell Biology, Shanghai Institutes for Biological Sciences, \\ Chinese Academy of Science, Shanghai 200031, P.R. China; ${ }^{3}$ Department of Radiation Oncology, \\ University of Pennsylvania School of Medicine, Philadelphia, PA 19104, USA
}

Received June 30, 2015; Accepted September 29, 2016

DOI: 10.3892/ol.2017.5651

\begin{abstract}
Thioridazine (TDZ), originally an anti-psychotic drug, suppresses several types of cancer and has specificity for leukemia stem cells. The present study was performed to assess its effect on lung cancer stem-like cells, as its effect remains unknown. TDZ was utilized to treat lung cancer stem-like cells (A549 sphere cells) and its cytotoxic effect and mechanism were evaluated in vitro and in vivo. TDZ elicited cytotoxicity in A549 sphere cells and inhibited their proliferation in a dose-dependent pattern. A549 sphere cells treated with TDZ showed nuclear fragmentation, increased G0/G1 phase distribution, positive Annexin V staining, and a change in the expression of caspase family and cell cycle-associated proteins. These results suggest the induction of caspase-dependent apoptosis and cell cycle arrest. In addition, TDZ treatment resulted in significant inhibitory effect on mice xenografts established by A549 sphere cells. TDZ repressed growth of lung cancer stem-like cells in vitro and in vivo, indicating its potential application in targeting lung cancer stem-like cells.
\end{abstract}

\section{Introduction}

Lung cancer is among the most common causes of cancer-associated mortality worldwide $(1,2)$, and the majority of cases are non-small cell lung cancer (NSCLC), which has

Correspondence to: Dr Yu Yang, Xinyuan Institute of Medicine and Biotechnology, School of Life Sciences, Zhejiang Sci-Tech University, 928 Second Avenue, Hangzhou, Zhejiang 310018, P.R. China E-mail: yvonneyang123@163.com

Dr Haineng Xu, Department of Radiation Oncology, University of Pennsylvania School of Medicine, 3400 Civic Center Boulevard, Philadelphia, PA 19104, USA

E-mail: xuhaineng123@163.com

Key words: thioridazine, lung cancer-stem like cells, A549 sphere cells, apoptosis, cell cycle arrest a poor 5-year survival rate (3). Previous studies hypothesized that the cancer stem-like cell (CSC) subpopulation resulted in cancer initiation, progression, drug resistance, metastasis and recurrence. Since CSCs were first found in leukemia (4), evidence for CSC existence has been emerging in a variety of cancers (5-7), including lung cancer (8-10). CSCs exhibited distinct characteristics, including self-renewal, differentiation, quiescence and heterogeneous tumorigenicity. These properties lead to traditional therapy failure, making CSCs crucial targets for successful cancer treatment (11).

Thioridazine (TDZ) was originally used as a treatment for psychotic disease $(12,13)$, and has also been used to treat against drug-resistant microorganisms $(14,15)$. A recent study reported the potent effect of TDZ on various types of cancer cells. TDZ was capable of inhibiting mucosa-associated lymphoid tissue lymphoma translocation protein 1 (MALT1) protease and provided potential applications in B cell lymphoma (16). It is also involved in the phosphoinositide 3-kinase (PI3K)/protein kinase B (Akt)/mechanistic target of rapamycin pathway, contributing to anti-angiogenesis effects and apoptosis in breast and ovarian $(17,18)$ cancers. In addition, TDZ induced cell death in cancers, including cervical (19), prostate (20), gastric (21) and pancreatic cancers (16). Additionally, TDZ has been shown to sensitize drug-resistance cancer cells by P-glycoprotein inhibition (22) and be a top chemotherapeutic for gefitinib-resistant NSCLC cells (23). Furthermore, TDZ has selectivity in leukemia and breast CSCs as a dopamine receptor inhibitor $(24,25)$.

Due to this background, the current study hypothesized that TDZ would exert cytotoxic effects on lung CSCs. In the present study, TDZ treatment was performed on lung cancer stem-like A549 sphere cells, which were established and characterized in our previous study (26). Cell viability and colony formation ability of A549 spheres reduced following TDZ treatment. Caspase-dependent apoptosis and G1 phase arrest were detected in TDZ-treated A549 sphere cells. In vivo experiments additionally showed that TDZ pretreatment inhibited initiation and growth of mice xenografts derived from A549 sphere cells, indicating it as a candidate for successful lung cancer therapy. 


\section{Materials and methods}

Cell culture and viability analysis. Human lung cancer stem-like A459 sphere cells were obtained and maintained as described in our previous study (26), with a growth factor-defined serum-free medium in ultra-low detachment 6-well plates. A549 cells were incubated with serum-free Dulbecco's modified Eagle medium: Nutrient mixture F-12 (GE Healthcare Life Sciences, Chalfont, UK) medium in ultra-low attachment 6-well dishes (Corning, Tewksbury, MA, USA). Growth factors including epidermal growth factor, basic fibroblast growth factor and insulin-like growth factor 1 were supplied at a concentration of $20 \mathrm{ng} / \mathrm{ml}$ (PeproTech, Rocky Hill, NJ, USA) each day (A549 sphere cells). Three days subsequent to seeding, the propagated spheroid bodies were collected and digested by StemPro Accutase (Thermo Fisher Scientific Inc., Waltham, MA, USA) to single cell suspension for subsequent experiments. Cell viability was observed by microscopy or crystal violet staining and quantitated by methyl thiazolyl tetrazolium (MTT) assay. Cells were seeded in 24 -well plates $\left(2 \times 10^{5}\right.$ cells/well) for direct observation and in the 96 -well plates $\left(1 \times 10^{4}\right.$ cells/well) for indirect quantitation, respectively. Following adherence, TDZ (Sigma-Aldrich; Merck Millipore, Darmstadt, Germany) was added at the indicated concentrations $(0,0.01,0.1,0.5,1,5$, 10 and $15 \mu \mathrm{M})$. Two days later, cells in 24-well plates were photographed with or without crystal violet staining. Cells in 96-well plates were incubated with $20 \mathrm{ml}$ MTT (Beyotime Institute of Biotechnology, Haimen, China) for another $4 \mathrm{~h}$ at $37^{\circ} \mathrm{C}$. Supernatants were discarded and $100 \mu 1$ dimethyl sulfoxide (DMSO; Guanghua Sci-Tech, Shanghai, China) was added to each well and agitated. Cell viability was assessed by absorbance of dual wavelength light $(490$ and $570 \mathrm{~nm})$ via a microplate reader (Tecan, Männedorf, Switzerland). All experiments were repeated 3 times.

Colony formation assay. Cells were plated in 6-well plates $\left(1 \times 10^{3}\right.$ cells/well) for colony formation. TDZ was applied to treated cells following adherence at indicated concentrations $(0,1,5,10$ and $15 \mu \mathrm{M})$. After 12 days, colonies were fixed and subjected to crystal violet staining for visualization. Images of plates containing colonies were captured using a Canon EOS 650D digital camera (Canon, Inc., Tokyo, Japan) and the number of colonies was counted. Experiments were repeated 3 times.

Hoechst staining. Cells in $96-$ well plates $\left(1 \times 10^{4}\right.$ cells/well $)$ received different treatments with TDZ $(0,1,10$ and $15 \mu \mathrm{M})$ for $48 \mathrm{~h}$. Cells were then fixed with $4 \%$ paraformaldehyde (Sigma-Aldrich; Merck Millipore) for $15 \mathrm{~min}$ and stained with $1 \mu \mathrm{g} / \mathrm{ml}$ Hoechst 33342 (Molecular Probes, Eugene, OR, USA) for $1 \mathrm{~min}$. Images of morphology were captured by fluorescence microscopy. Experiments were repeated 3 times.

Flow cytometry. Cells were digested following a 1-day treatment with TDZ $(0,1,10$ and $15 \mu \mathrm{M})$. For cell cycle analysis, cells were fixed with $70 \%$ ethanol at $4^{\circ} \mathrm{C}$ for $1 \mathrm{~h}$ subsequent to being washed and resuspended in phosphate-buffered saline. Cells were then centrifuged at 1,000 $\mathrm{x} g$ for $3 \mathrm{~min}$ at room temperature, prior to washing and incubation with $20 \mu \mathrm{g} / \mathrm{ml}$ RNase A (Generay, Shanghai, China) for $30 \mathrm{~min}$ at $37^{\circ} \mathrm{C}$ in a water bath. Subsequently, cells were stained for $30 \mathrm{~min}$ with $50 \mu \mathrm{g} / \mathrm{ml}$ PI (Sigma-Aldrich; Merck Millipore). For Annexin V/PI staining, cells were prepared using Annexin V-fluorescein isothiocyanate Apoptosis Detection kit (eBioscience, San Diego, CA, USA), according to the manufacturer's protocol. The fluorescence-activated cell sorting results were collected using Accuri ${ }^{\mathrm{TM}}$ C6 (BD Biosciences, Franklin Lakes, NJ, USA).

Western blotting. Western blotting was conducted according to the standard procedures. Primary antibodies against survivin [cat no. 2808; rabbit monoclonal antibody (mAb); 1:1,000], cyclin-dependent kinase 2 (CDK2; cat no. 2546; rabbit mAb; 1:1,000), Akt (cat no. 9272; Rabbit; 1:1,000), phosphorylated-Akt (Ser473) (D9E) (cat no. 4060; rabbit mAb; 1:2,000), caspase-8 precursor (caspase8; cat no. 9746; mouse $\mathrm{mAb} ; 1: 500)$, and poly ADP-ribose polymerase (PARP; cat no. 9532; rabbit $\mathrm{mAb}$; 1:1,000) were purchased from Cell Signaling Technology (Beverly, MA, USA). GAPDH (cat no. CW0100M; mouse mAb; 1:3,000) was from CoWin Bioscience (Beijing, China). Secondary antibodies including mouse anti goat IgG-HRP (cat no. sc-2354; goat; 1:5,000) and rabbit anti goat IgG-HRP (cat no. sc-2922; goat; 1:5,000) were purchased from Santa Cruz Biotechnology (Dallas, TX, USA).

Animal experiments. A total of 36 four-week old female $\mathrm{BALB} / \mathrm{c}$ nude mice were purchased from the Shanghai Laboratory Animal Centre and raised in specific pathogen free conditions at the animal facility of Shanghai Institute of Biochemistry and Cell Biology (both Shanghai, China). All animal experiments were performed based on the corresponding policy approved by the Institutional Animal Care and Use Committee. To explore the in vivo anti-tumor effect of TDZ, A549 sphere cells were pretreated with DMSO, 1 or $10 \mu \mathrm{M}$ DZ for $24 \mathrm{~h}$. Cells were then mixed with Matrigel (2:1; BD Biosciences) and injected subcutaneously into the right rear of nude mice $\left(2 \times 10^{5}\right.$ cells/mouse) following digestion and counting. Each group consisted of 6 mice. The tumor volumes were measured using Vernier calipers every 3 days and calculated as follows: Volume $\left(\mathrm{mm}^{3}\right)=$ length $\mathrm{x}$ width $\mathrm{x}$ width / 2 .

Statistical analysis. All the data were presented as the mean \pm standard deviation (SD) or mean $+\mathrm{SD}$. R software was utilized for Student's t-test or one-way analysis of variance to compare the difference among groups. The non-parametric Friedman test was used to analyze differences, followed by the Dunn's Multiple Comparison test. $\mathrm{P}<0.05$ was considered to indicate a statistically significant difference.

\section{Results}

TDZ exhibited cytotoxicity in lung CSCs. Lung cancer stem-like A549 sphere cells were obtained as described in materials and methods. The cytotoxic effect of TDZ on A549 sphere cells was analyzed. Morphological alteration appeared in A549 sphere cells treated with TDZ (Fig. 1A). A concentration-dependent 
A

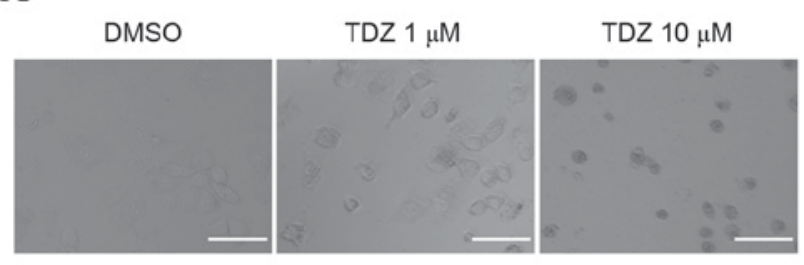

B

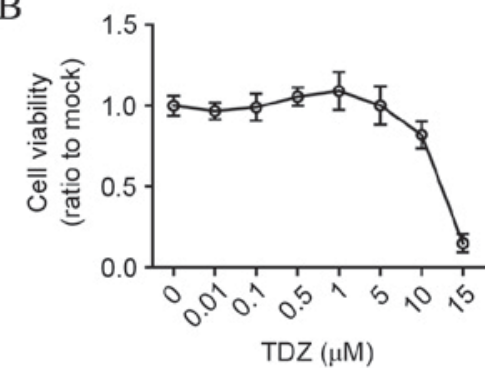

$\mathrm{C}$

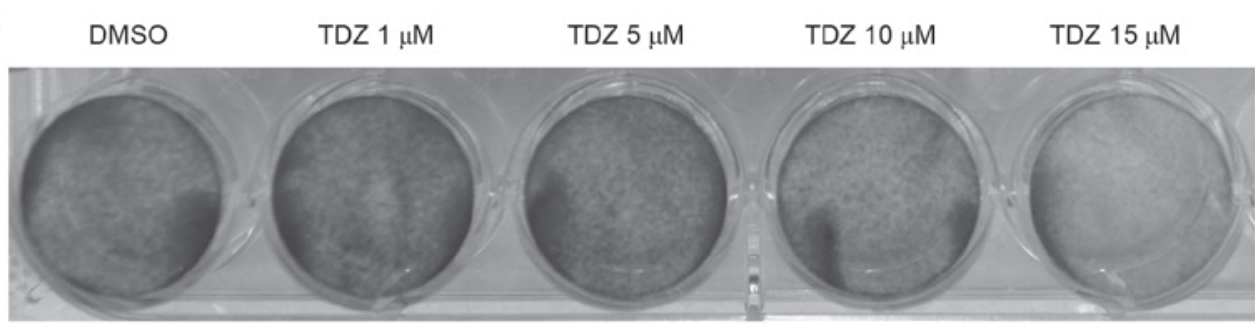

D

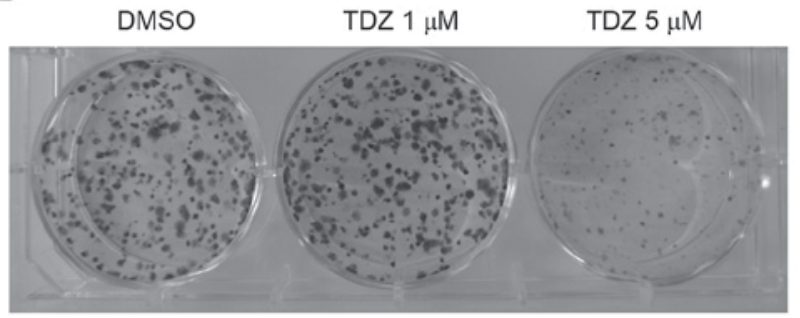

$\mathrm{E}$

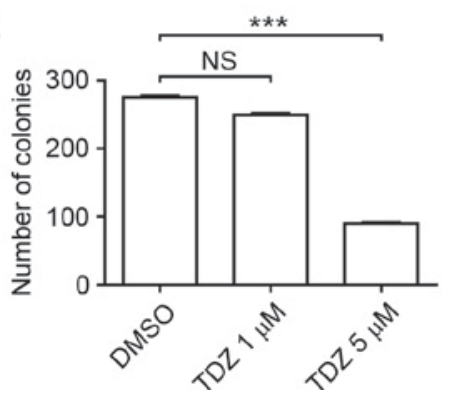

Figure 1. TDZ exhibits cytotoxicity in lung CSCs. (A) Morphology of A549 sphere cells altered following treatment with 1 or $10 \mu \mathrm{M}$ TDZ for $48 \mathrm{~h}$. Scale bar, $200 \mu \mathrm{m}$. (B) Cell viability of A549 sphere cells decreased in a dose-dependent manner following TDZ treatment $(0.01,0.1,0.5,1,5,10$ or $15 \mu \mathrm{M})$ for $48 \mathrm{~h}$. Cell viability was determined by MTT assay (C) TDZ attenuated A549 sphere cell viability. A549 sphere cells were treated with TDZ (1, 5, 10 or $15 \mu$ M) for $48 \mathrm{~h}$ and then subjected to crystal violet staining. (D) TDZ-treated A549 sphere cells formed fewer colonies, as shown by crystal violet staining. (E) Statistical analysis of colony formation assay. The y-axis indicated the total number of colonies in 1 well. All experiments were repeated three times with DMSO as a control. All data shown are expressed as the mean \pm standard deviation $(n=3) .{ }^{* * *} \mathrm{P}<0.001$. TDZ, thioridazine; DMSO, dimethyl sulfoxide; NS, no significance.

curve of TDZ against cell viability through MTT assay indicated that a high dose of TDZ significantly impacted cell growth (Fig. 1B), which was consistent with the result of crystal violet staining (Fig. 1C). Similarly, the colony formation ability of A549 sphere cells was markedly decreased by TDZ (Fig. 1D and E), inferring the dose-dependent inhibitory effect of TDZ on lung CSCs.

TDZ induced apoptosis and cell cycle arrest in A549 sphere cells. To investigate the mechanism of cell death and proliferation inhibition, A549 sphere cells were stained by Hoechst 33342 following addition of TDZ. Significant nuclear fragmentation was observed in cells under stress of high dose TDZ compared with the DMSO-treated control (Fig. 2A). The percentage of Annexin $\mathrm{V}$-positive cells rose with the growing concentration of TDZ (Fig. 2B). Overall, these findings provided evidence that TDZ induced apoptosis in A549 sphere cells. In addition, cell-cycle phase distribution was analyzed. The proportion of cells in the G0/G1 phase enlarged as the dose of TDZ increased (Fig. 2C), indicating that TDZ was associated with G1/S checkpoint activation and cell cycle arrest.
TDZ induced caspase-dependent apoptosis and Akt-associated cell cycle arrest. To additionally clarify the mechanism of apoptosis and cell cycle arrest, expression levels of associated proteins were examined by western blot. Decrease of procaspase 8 and PARP expression was detected in TDZ-treated A549-sphere cells along with apoptosis repressors, such as survivin (Fig. 3A). Additionally, the protein levels of cell cycle-associated pathways, including Akt, p-Akt and CDK2, were downregulated (Fig. 3B). These results indicated that TDZ induced cell death of A549 sphere cells via caspase-dependent apoptosis and inhibited cell proliferation through the Akt-CKD2 pathway.

TDZ suppressed tumor initiation and growth in vivo. The in vivo activity of TDZ on lung CSCs were tested based on a mice xenograft model. In comparison to the control, TDZ-pretreated A549 sphere cells showed increased latency time on xenograft initiation with increasing TDZ concentration (Fig. 4A). Although low dose TDZ treatment $(1 \mu \mathrm{M})$ presented little effect on A549 sphere cell viability in vitro, the two doses of TDZ treatment (1 and $10 \mu \mathrm{M})$ showed significant inhibition of the growth of mice xenografts derived by A549 sphere cells 
A

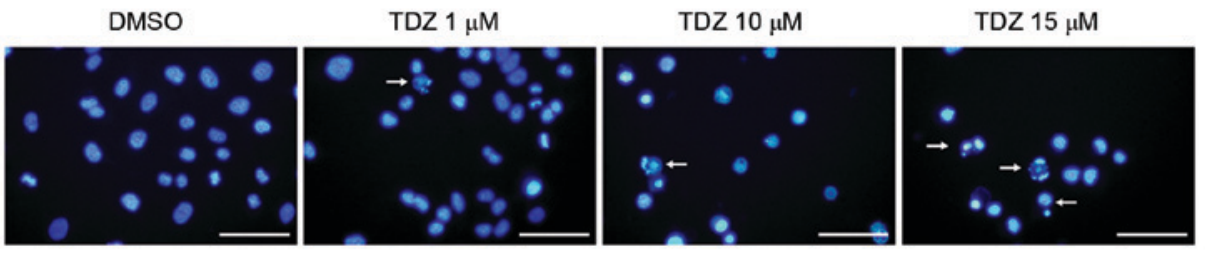

B

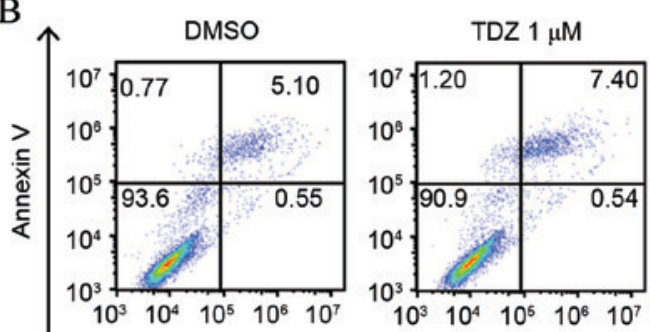

TDZ $10 \mu \mathrm{M}$
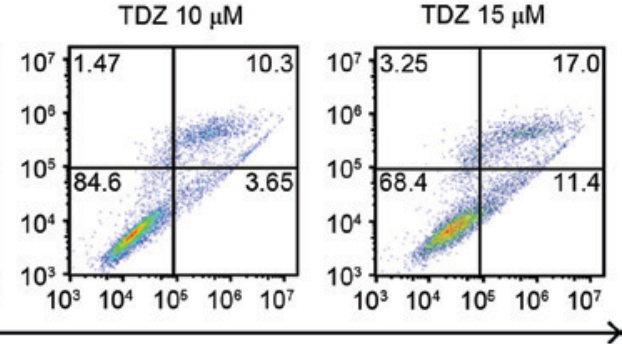

C
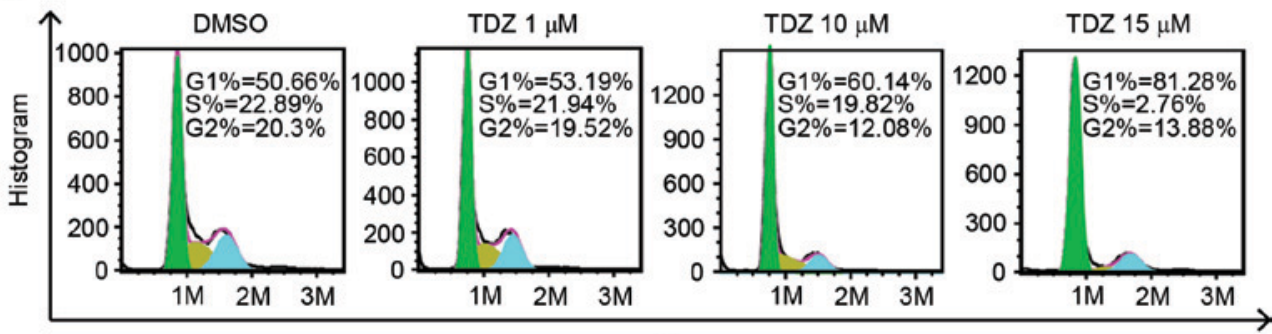

$\mathrm{PI}$

Figure 2. TDZ induced apoptosis and cell cycle arrest in A549 sphere cells. (A) Increased nucleic fragmentation (arrow) was observed in A549 sphere cells following 2-day treatment with TDZ (1, 10 or $15 \mu \mathrm{M})$, as detected by Hoechst staining. Scale bar, $200 \mu \mathrm{m}$. (B) Apoptosis was detected in TDZ-treated (1, 10 or $15 \mu \mathrm{M}$ ) A549 sphere cells by Annexin V/PI double staining with fluorescence-activated cell sorting analysis. (C) G1-phase cell proportion increased with concentration of TDZ treatment $(1,10$ or $15 \mu \mathrm{M})$ on A549 sphere cells. The areas of green, yellow and blue equaled the percentage of cells in G1, S and G2 phase, respectively. All experiments were repeated three times with DMSO as a control. TDZ, thioridazine; PI, propidium iodide; DMSO, dimethyl sulfoxide.

A

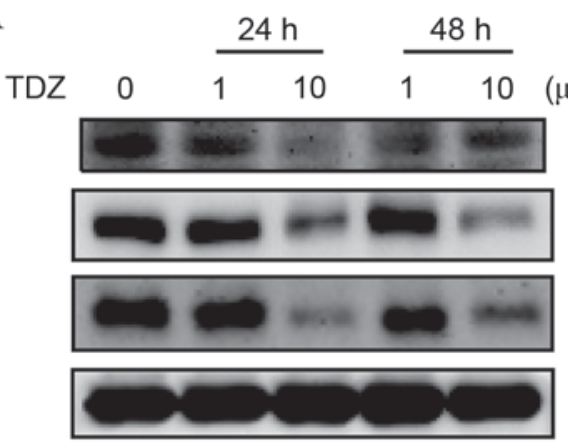

$(\mu \mathrm{M})$

Procaspase8

PARP

Survivin

GAPDH
B

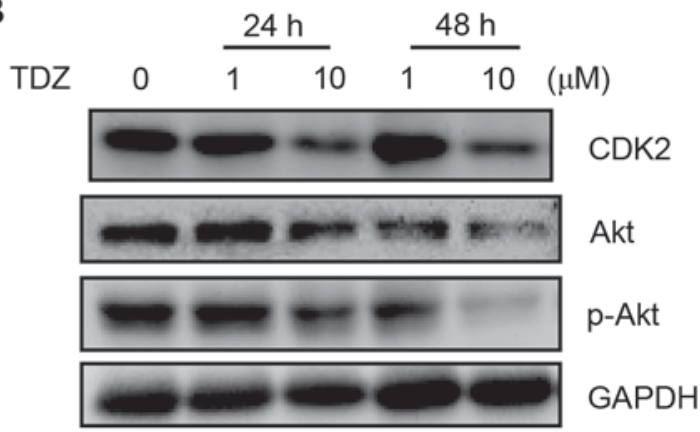

Figure 3. TDZ induced caspase-dependent apoptosis and Akt-CDK2 associated cell cycle progression. (A) Decreased expression of apoptosis-associated proteins, including procaspase8, PARP and survivin, in A549-sphere cells treated with TDZ was detected using western blotting. (B) Decreased expression of cell cycle associated proteins, including CDK2, Akt and p-Akt, in A549-sphere cells treated with TDZ was detected using western blotting. All experiments were repeated three times with GAPDH as a loading control. TDZ, thioridazine; PARP, poly ADP-ribose polymerase; GAPDH, glyceraldehyde 3-phosphate dehydrogenase; CDK2, cyclin-dependent kinase 2; Akt, protein kinase B; p-Akt, phosphorylated-protein kinase B.

(Fig. 4B-D). Overall, these data disclosed the in vivo effect of TDZ on repression of tumor initiation and progression.

\section{Discussion}

To the best of our knowledge, the present study investigated for the first time the effect of TDZ on lung CSCs. As more evidence for CSC existence is being found, novel chemotherapeutics can be developed for CSC targeting. Akt is a key regulator of cell proliferation, metabolism, survival and apoptosis, and inhibitors for Akt are able to target CSCs in breast cancer (27) and liver cancer (28). TDZ, previously used for patients with psychotic illnesses, is an antagonist of dopamine receptor $\mathrm{D}_{2}$ family proteins, which has interactions with 
A

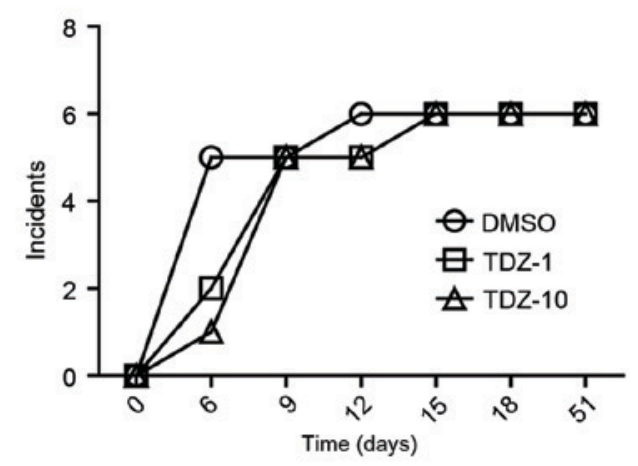

$\mathrm{C}$

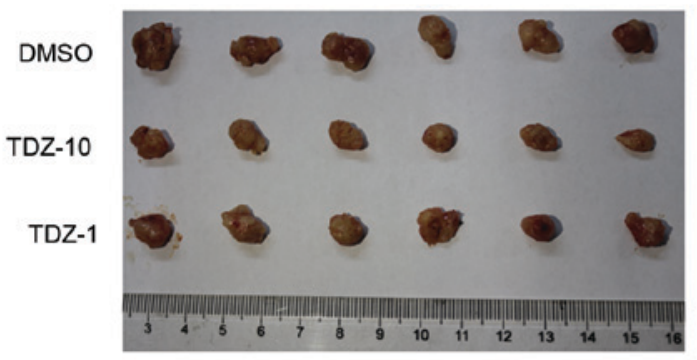

B
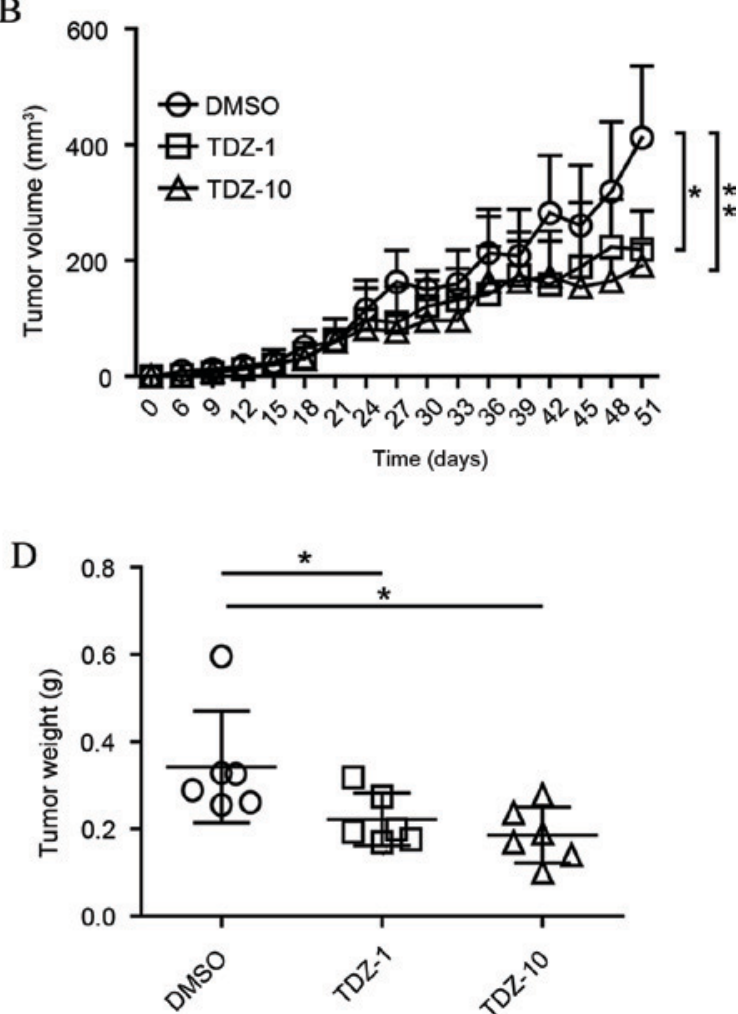

Figure 4. TDZ suppressed tumor initiation and growth in vivo. (A) Comparison of tumor initiating ability on A549 sphere cells pre-treated with DMSO or TDZ (1 or $10 \mu \mathrm{M})$. The number of tumors was plotted against time following inoculation (day 0 ). The incidence indicated the number of mice with palpable tumor. (B) Growth curve of subcutaneous tumors with the indicated pre-treatment. (C) Tumor morphology with different treatments on day 51. (D) Measurement of tumor weights with indicated treatments on day 51. Tumor volume was measured every 3 days and the data shown represent the mean \pm SD or mean + SD $(\mathrm{n}=6)$. The number of mice for each type of treatment was $6 .{ }^{*} \mathrm{P}<0.05,{ }^{* *} \mathrm{P}<0.01$. TDZ, thioridazine; DMSO, dimethyl sulfoxide; SD, standard deviation; TDZ-1, thioridazine $1 \mu \mathrm{M}$; TDZ-10, thioridazine $10 \mu \mathrm{M}$.

Akt (29). It has been reported that TDZ was able to inhibit the PI3K/Akt pathway (30) and induce cell death in various cancer cells. TDZ treatment selectively affected leukemia CSCs rather than normal stem cells (24), suggesting TDZ as a potent therapeutic agent for CSCs. In the present study, the Akt protein level decreased following TDZ-treatment, which was consistent with the aforementioned studies and its downregulated phosphorylation level may explain the apoptosis and G1/S arrest presented following TDZ treatment (Figs. 2 and 3 ).

Isolation and identification of CSCs is required for evaluating targeted drugs. Cell sorting and specific culture are the main methods used to isolate CSCs. A549 sphere cells were enriched and demonstrated to have lung CSC properties in our previous study (26). In the current study, TDZ exhibited anti-proliferation activity in A549 sphere cells and altered their cell viability (Fig. 1). Notably, despite the fact that low-dose TDZ treatment was not efficient in vitro, it performed well in terms of tumor xenograft repression in vivo (Fig. 4). The anti-angiogenesis mechanism may contribute to the discrepancy, as TDZ is capable of affecting vascular endothelial growth factor receptor 2 (18). Furthermore, TDZ has the capacity of relieving drug resistance of cancer cells, indicating that combination of other therapeutics may achieve improved results. In addition, TDZ promoted cancer cell death induced by oncolytic adenovirus (31), inferring its potential application with gene-virotherapy.

In conclusion, the present data illustrates that TDZ shows robust inhibitory effect on lung CSCs in vitro and in vivo, indicating its utility as a promising candidate drug for lung CSC-targeted therapy.

\section{Acknowledgements}

The authors thank the staff at the Cell Biology Platform for their assistance in flow cytometry assays. This study was supported by National Natural Science Fund (grant no. 81272687) and Zhejiang Provincial Natural Science Foundation of China (grant no. LZ13H160004).

\section{References}

1. Siegel RL, Miller KD and Jemal A: Cancer Statistics, 2015. CA Cancer J Clin 65: 5-29, 2015

2. She J, Yang P, Hong Q and Bai C: Lung cancer in China: Challenges and interventions. Chest 143: 1117-1126, 2013.

3. Chen Z, Fillmore CM, Hammerman PS, Kim CF and Wong KK: Non-small-cell lung cancers: A heterogeneous set of diseases. Nat Rev Cancer 14: 535-546, 2014.

4. Lapidot T, Sirard C, Vormoor J, Murdoch B, Hoang T, Caceres-Cortes J, Minden M, Paterson B, Caligiuri MA and Dick JE: A cell initiating human acute myeloid leukaemia after transplantation into SCID mice. Nature 367: 645-648, 1994.

5. Al-Hajj M, Wicha MS, Benito-Hernandez A, Morrison SJ and Clarke MF: Prospective identification of tumorigenic breast cancer cells. Proc Natl Acad Sci USA 100: 3983-3988, 2003.

6. Singh SK, Clarke ID, Terasaki M, Bonn VE, Hawkins C, Squire $\mathrm{J}$ and Dirks PB: Identification of a cancer stem cell in human brain tumors. Cancer Res 63: 5821-5828, 2003.

7. Ricci-Vitiani L, Lombardi DG, Pilozzi E, Biffoni M, Todaro M, Peschle $C$ and De Maria R: Identification and expansion of human colon-cancer-initiating cells. Nature 445: 111-115, 2007. 
8. Eramo A, Lotti F, Sette G, Pilozzi E, Biffoni M, Di Virgilio A, Conticello C, Ruco L, Peschle C and De Maria R: Identification and expansion of the tumorigenic lung cancer stem cell population. Cell Death Differ 15: 504-514, 2008.

9. Roudi R, Madjd Z, Korourian A, Mehrazma M, Molanae S, Sabet MN and Shariftabrizi A: Clinical significance of putative cancer stem cell marker CD44 in different histological subtypes of lung cancer. Cancer Biomark 14: 457-467, 2014.

10. Liu CC, Lin JH, Hsu TW, Su K, Li AF, Hsu HS and Hung SC: IL-6 enriched lung cancer stem-like cell population by inhibition of cell cycle regulators via DNMT1 upregulation. Int J Cancer 136: 547-559, 2015.

11. Zhou BB, Zhang HY, Damelin M, Geles KG, Grindley JC and Dirks PB: Tumour-initiating cells: Challenges and opportunities for anticancer drug discovery. Nat Rev Drug Discovery 8: 806-823, 2009.

12. Ohman R and Axelsson R: Relationship between prolactin response and antipsychotic effect of thioridazine in psychiatric-patients. Eur J Clin Pharmacol 14: 111-116, 1978.

13. Realmuto GM, Erickson WD, Yellin AM, Hopwood JH and Greenberg LM: Clinical comparison of thiothixene and thioridazine in schizophrenic adolescents. Am J Psychiatry 141: 440-442, 1984.

14. van Soolingen D, Hernandez-Pando R, Orozco H, Aguilar D, Magis-Escurra C, Amaral L, van Ingen $\mathrm{J}$ and Boeree $\mathrm{MJ}$ : The antipsychotic thioridazine shows promising therapeutic activity in a mouse model of multidrug-resistant tuberculosis. PLoS One 5: e12640, 2010.

15. Thorsing M, Klitgaard JK, Atilano ML, Skov MN, Kolmos HJ, Filipe SR and Kallipolitis BH: Thioridazine induces major changes in global gene expression and cell wall composition in methicillin-resistant Staphylococcus aureus USA300. PLoS One 8: e64518, 2013.

16. Nagel D, Spranger S, Vincendeau M, Grau M, Raffegerst S, Kloo B, Hlahla D, Neuenschwander M, Peter von Kries J, Hadian K, et al: Pharmacologic inhibition of MALT1 protease by phenothiazines as a therapeutic approach for the treatment of aggressive ABC-DLBCL. Cancer Cell 22: 825-837, 2012.

17. Byun HJ, Lee JH, Kim BR, Kang S, Dong SM, Park MS, Lee SH, Park SH and Rho SB: Anti-angiogenic effects of thioridazine involving the FAK-mTOR pathway. Microvascular Res 84: 227-234, 2012.

18. Park MS, Dong SM, Kim BR, Seo SH, Kang S, Lee EJ, Lee SH and Rho SB: Thioridazine inhibits angiogenesis and tumor growth by targeting the VEGFR-2/PI3K/mTOR pathway in ovarian cancer xenografts. Oncotarget 5: 4929-4934, 2014.

19. Kang S, Dong SM, Kim BR, Park MS, Trink B, Byun HJ and Rho SB: Thioridazine induces apoptosis by targeting the $\mathrm{PI} 3 \mathrm{~K} / \mathrm{Akt} / \mathrm{mTOR}$ pathway in cervical and endometrial cancer cells. Apoptosis 17: 989-997, 2012.
20. Csonka A, Spengler G, Martins A, Ocsovszki I, Christensen JB, Hendricks O, Kristiansen JE, Amaral L and Molnar J: Effect of thioridazine stereoisomers on the drug accumulation of mouse lymphoma and human prostate cancer cell lines in vitro. In vivo 27: 815-820, 2013

21. Mu J, Xu H, Yang Y, Huang W, Xiao J, Li M, Tan Z, Ding Q, Zhang L, Lu J, et al: Thioridazine, an antipsychotic drug, elicits potent antitumor effects in gastric cancer. Oncol Rep 31: 2107-2114, 2014

22. Spengler G, Molnar J, Viveiros M and Amaral L: Thioridazine induces apoptosis of multidrug-resistant mouse lymphoma cells transfected with the human ABCB1 and inhibits the expression of P-glycoprotein. Anticancer Res 31: 4201-4205, 2011.

23. Sudo M, Mori S, Madan V, Yang H, Leong G and Koeffler HP: Short-hairpin RNA library: Identification of therapeutic partners for gefitinib-resistant non-small cell lung cancer. Oncotarget 6: 814-824, 2015.

24. Sachlos E, Risueño Ruth M, Laronde S, Shapovalova Z, Lee JH, Russell J, Malig M, McNicol JD, Fiebig-Comyn A, Graham M, et al: Identification of drugs including a dopamine receptor antagonist that selectively target cancer stem cells. Cell 149: 1284-1297, 2012.

25. Ke XY, Lin Ng VW, Gao SJ, Tong YW, Hedrick JL and Yang YY: Co-delivery of thioridazine and doxorubicin using polymeric micelles for targeting both cancer cells and cancer stem cells. Biomaterials 35: 1096-1108, 2014.

26. Yang Y, Xu HN, Huang WD, Ding M, Xiao J, Yang D, Li H, Liu XY and Chu L: Targeting lung cancer stem-like cells with TRAIL gene armed oncolytic adenovirus. J Cell Mol Med 19: 915-923, 2015

27. Korkaya H, Paulson A, Charafe-Jauffret E, Ginestier C, Brown M, Dutcher J, Clouthier SG and Wicha MS: Regulation of mammary stem/progenitor cells by PTEN/Akt/beta-catenin signaling. PLoS Biol 7: e1000121, 2009.

28. Zhang XL, Jia Q, Lv L, Deng T and Gao J: Tumorspheres derived from HCC Cells are enriched with cancer stem cell-like cells and present high chemoresistance dependent on the Akt pathway. Anticancer Agents Med Chem 15: 755-763, 2015.

29. Arguello PA and Gogos JA: A signaling pathway AKTing up in schizophrenia. J Clin Investig 118: 2018-2021, 2008.

30. Rho SB, Kim BR and Kang S: A gene signature-based approach identifies thioridazine as an inhibitor of phosphatidylinositol-3'-kinase (PI3K)/AKT pathway in ovarian cancer cells. Gynecol Oncol 120: 121-127, 2011.

31. Dongmei D, Xianlong F, Yu Y, Hongyan L, Qiang P and Haineng X: Inhibition of HeLa Cells by the combination of Thioridazine and Oncolytic Adenovirus ZD55-TRAIL and the exploration of its mechanism. Chinese J Cell Biol 36: 595-601, 2014 